\title{
Consciência fonêmica em meninos e meninas
}

\author{
Phonemic awareness in boys and girls
}

\author{
Simone Raquel Sbrissa Moura ${ }^{1}$, Carla Aparecida Cielo², Carolina Lisbôa Mezzomoº
}

\begin{abstract}
RESUMO
Objetivo: Verificar a interferência da variável sexo no desempenho de tarefas em consciência fonêmica. Métodos: A amostra constituiu-se de 36 estudantes da segunda série do Ensino Fundamental, sendo 18 meninas e 18 meninos. Todos foram submetidos à triagem audiológica, avaliação fonoaudiológica e das habilidades em consciência fonêmica. Resultados: De modo geral, a análise estatística não apontou diferenças significantes entre os sexos. No entanto, qualitativamente, observou-se que as crianças do sexo feminino apresentaram mais êxito do que os sujeitos do sexo masculino, em todas as tarefas de segmentação e de síntese fonêmica, que repercutem na análise de elementos menores. Conclusões: Embora não tenham sido observadas diferenças estatisticamente significantes entre os sexos, constatou-se que o grupo das meninas apresentou melhor desempenho nas habilidades em consciência fonêmica.
\end{abstract}

Descritores: Linguagem; Estudantes; Criança; Fonoterapia; Distribuição por sexo

\section{INTRODUÇÃO}

A consciência fonológica é entendida como a consciência de que as palavras são constituídas por uma sequiência de sons e que se desenvolve gradualmente na infância como parte da habilidade metalinguística, isto é, da capacidade de reflexão sobre a linguagem como um objeto ${ }^{(1)}$.

Pesquisas sustentam que, para que a criança aprenda a ler e a escrever no sistema de escrita alfabético, é necessário que ela perceba a relação entre os fonemas e os grafemas. Para isso, são fundamentais as habilidades em análise, síntese e manipulação dos componentes fonológicos da fala, que compõem a consciência fonológica ${ }^{(2-3)}$.

Muitos autores concordam que existe uma sequiência de complexidade dependente da unidade linguística que é manipulada. Com relação à Língua Portuguesa, pressupõe-se a seguinte ordem de habilidades, em um crescente de dificuldade: consciência sobre palavras; consciência de rimas; consciência silábica e consciência fonêmica ${ }^{(2,4)}$. As mesmas pesquisas que apontam essa seqüência, também consideram que a capacidade de operar com fonemas constitui a tarefa mais complexa.

Trabalho realizado no Departamento de Fonoaudiologia da Universidade Federal de Santa Maria - UFMS - Santa Maria (RS), Brasil.

(1) Mestre, Professora do Curso Pós-graduação Lato Sensu em Fonoaudiologia Hospitalar do Instituto Fisiomar - IF - Itajaí (SC), Brasil.

(2) Doutora, Professora Adjunto do Departamento de Fonoaudiologia da Universidade Federal de Santa Maria - UFMS - Santa Maria (RS), Brasil.

(3) Doutora, Professora Adjunto da Fundação Faculdade Federal de Ciências Médicas de Porto Alegre - FFFCMPA - Porto Alegre (RS), Brasil.

Endereço para correspondência: Simone Raquel Sbrissa Moura. R. Dr. Nereu Ramos, 120/1002, Centro, Itajaí - SC, CEP: 88301-215. E-mail: simoneraquel77@hotmail.com.

Recebido em: 19/3/2008; Aceito em: 28/9/2008
Assim, são considerados quatro níveis diferenciados de habilidades em consciência fonológica, que se desenvolvem por meio do ensino formal da escrita ou espontaneamente: habilidades em consciência de palavras, de rimas, de sílabas e de fonemas ${ }^{(2)}$.

A habilidade em analisar e manipular de modo consciente os fonemas caracteriza o nível das habilidades em consciência fonêmica ${ }^{(5)}$. Por se tratar das menores unidades da língua, sem significado, os fonemas são mais dificilmente percebidos ou conceituados pelas crianças do que as palavras ou as sílabas ${ }^{(6)}$. Desse modo, considera-se que a aprendizagem e o domínio do código alfabético influenciam as habilidades que envolvem a consciência fonêmica ${ }^{(1-2)}$.

Pesquisas indicam que, sem instrução direta, aproximadamente $25 \%$ dos estudantes de primeira série do Ensino Fundamental não desenvolvem a consciência fonêmica. Além disso, esses sujeitos podem apresentar muitas dificuldades para aprender a ler e a escrever ${ }^{(7)}$. O nível de consciência fonêmica de uma criança ao ingressar na escola, é considerado um indicador individual bastante eficaz do êxito ou do não êxito que ela terá ao aprender a ler ${ }^{(8-9)}$.

Estudos que investigaram a importância da consciência fonêmica para o desenvolvimento da leitura e da escrita mostraram que tal habilidade constitui um aspecto-chave na alfabetização ${ }^{(10)}$.

Em pesquisa com crianças falantes do Português Brasileiro, comparando a identificação e manipulação silábicas e fonêmicas, a consciência fonêmica é apontada como o fator mais preditivo de êxito para a leitura em Português do que a sílaba $^{(11)}$.

Nas últimas duas décadas, diversos estudos relacionando consciência fonológica ao aprendizado da leitura e da escrita 
vêm sendo realizados. Entretanto, poucos tratam especificamente da habilidade em consciência fonêmica e descrevem a influência da variável sexo no seu desenvolvimento. Isto é, o critério binário, meninos e meninas, é pouco explorado como sendo uma variável no resultado do desempenho em tarefas de consciência fonêmica ${ }^{(12)}$.

Há evidências científicas de que existem diferenças significativas entre os sexos quanto à aquisição do sistema fonológico $^{(13)}$ favorável aos meninos. Nas meninas, por outro lado, encontra-se maior número de produções durante a expressão oral, melhor discriminação auditiva, maior coordenação visomotora, e melhor desempenho inicial na aquisição da leitura e da escrita ${ }^{(13-14)}$. Pesquisas apontam, inclusive, que a proporção de meninos com dislexia é maior com relação às meninas ${ }^{(15)}$.

De acordo com exames de neuroimagem, as mulheres processam melhor a linguagem que os homens ${ }^{(16)} \mathrm{e}$ esse argumento talvez explique as diferenças observadas entre os sexos. Há sinais de que, ao tratar com material fonológico, o sexo feminino processa a linguagem verbal nos dois hemisférios cerebrais ao mesmo tempo, enquanto que os homens utilizam áreas específicas do hemisfério dominante ${ }^{(13)}$.

Alguns autores observaram que as áreas de Broca e de Wernicke, relacionadas à fala, são maiores nas mulheres, o que também poderia justificar, biologicamente, um melhor desempenho do sexo feminino nas atividades associadas à linguagem ${ }^{(17)}$.

Além disso, pesquisadores acreditam que o lóbulo parietal inferior direito, área associada ao processo de atenção e percepção seletiva, bem como à capacidade de concentrar-se em um estímulo específico e em detalhes, parece sutilmente maior em mulheres ${ }^{(18)}$.

Embora estudos sobre o desenvolvimento normal da linguagem apontem que a variável sexo não interfere no processo de domínio fonológico, já se observou essa influência a favor dos meninos na produção correta de todos os fonemas em $\operatorname{coda}^{(19)}$.

Em relação ao desempenho em consciência fonológica, há evidências de que não existem diferenças entre meninos e meninas ${ }^{(20-21)}$. No entanto, estudos recentes ${ }^{(22-23)}$, utilizando distintos instrumentos de avaliação das habilidades em consciência fonológica, constataram diferenças significativas entre o desempenho do sexo masculino e do feminino.

Observa-se que o desempenho das meninas é superior em tarefas envolvendo segmentação silábica ${ }^{(22-23)}$ e detecção silábica ${ }^{(23)}$. Além disso, os achados também revelam diferenças qualitativas, no desempenho em tarefas de consciência de rimas, de sílabas e de fonemas, a favor do sexo feminino. Em contrapartida, parece que os meninos apresentam maior facilidade nas tarefas envolvendo consciência de palavras ${ }^{(23)}$.

Verifica-se que a interferência da variável sexo no desempenho das habilidades em consciência fonológica e, especificamente, em consciência fonêmica, é um tema ainda pouco explorado. Logo, há necessidade de maior número de pesquisas sobre tais diferenças, no sentido de melhor compreender sua relevância quanto ao processo de aprendizagem da leitura e da escrita.

Desta forma, esta pesquisa teve como objetivo verificar as diferenças e semelhanças de meninos e meninas, da segunda série do Ensino Fundamental, no desempenho em tarefas de consciência fonêmica, ou seja, a interferência da variável sexo no desempenho destas habilidades. Destaca-se que a opção pela terminologia "sexo" e não "gênero" se deve ao desejo de contemplar apenas a característica binária meninos e meninas, sem enfocar os aspectos socialmente determinados ${ }^{(12)}$.

A opção por verificar o desempenho em tarefas de consciência fonêmica de estudantes da segunda série do Ensino Fundamental justifica-se pelo fato de que a consciência fonêmica apresenta-se consolidada na faixa etária entre sete e oito anos, idades dos alunos deste nível de escolaridade ${ }^{(2)}$.

\section{MÉTODOS}

Este trabalho foi aprovado pelo Comitê de Ética em Pesquisa da Universidade Federal de Santa Maria - UFSM (número 0037.0.243.000-06). Também foi apresentado e autorizado pela direção da escola envolvida por meio do Termo de Autorização Institucional (CONEP - Res.196/96).

Para a seleção da amostra, foram considerados os seguintes critérios de inclusão: apresentar o Termo de Consentimento Livre e Esclarecido (CONEP - Res. 196/96) assinado pelos pais ou responsáveis, ter idades entre sete e oito anos, cursar a segunda série do Ensino Fundamental. Para apartar fatores que pudessem influenciar o desempenho das tarefas de consciência fonêmica considerou-se como critérios de exclusão da pesquisa: apresentar alterações neurológicas, emocionais e/ou perceptivas aparentes, e/ou doenças congênitas; apresentar desempenho negativo em triagem audiológica e fonoaudiológica; alterações na anatomofisiologia dos órgãos fonoarticulatórios, da linguagem oral expressiva e compreensiva e/ ou, da audição.

A triagem fonoaudiológica para a implementação dos critérios de exclusão incluiu: triagem audiológica, avaliação de linguagem, de fala e de motricidade orofacial. Os dados sobre as características emocionais e o nível intelectual dos alunos foram obtidos por meio dos pareceres realizados pelo serviço de psicologia escolar da instituição por meio de consulta ao prontuário escolar.

As crianças que apresentaram alterações nas avaliações de fala, de voz, de linguagem e de motricidade orofacial, foram encaminhadas para atendimento fonoaudiológico e excluídas do estudo.

O grupo de estudo formou-se com 36 alunos, 18 meninos e 18 meninas, em idades de 7:2 a 8:8 anos (média de idade: 7:5), estudantes da segunda série do Ensino Fundamental, sem alterações neurológicas, emocionais e/ou perceptivas aparentes, e/ ou doenças congênitas; com desempenho esperado na triagem audiológica e fonoaudiológica e sem alterações da linguagem oral e na anatomofisiologia dos órgãos fonoarticulatórios.

Para a coleta de dados foram avaliadas as habilidades em consciência fonêmica por intermédio do Protocolo de Tarefas de Consciência Fonológica ${ }^{(2)}$, do qual foram selecionadas e aplicadas apenas as tarefas envolvendo as habilidades em consciência fonêmica. São elas: exclusão, detecção, síntese, segmentação, e reversão de fonemas. As tarefas foram aplicadas individualmente, em sala silenciosa dentro da própria escola, em apenas uma sessão ou encontro, em tempo médio de aproximadamente 30 minutos. 
A aplicação do teste foi feita em conformidade com as normas sugeridas pela autora e as respostas foram tabuladas como corretas em primeira tentativa $\left(1^{\mathrm{a}} \mathrm{T}\right)$, com valor 2 ; corretas em segunda tentativa $\left(2^{\mathrm{a}} \mathrm{T}\right)$ com valor 1 ; ou incorretas, com valor 0 (zero). Cada subtipo de tarefas poderia ter, no máximo, dez pontos. Assim, foi possível obter escores para cada subtarefa e o escore bruto máximo de cada sujeito. Todos os resultados e escores de todas as crianças participantes da amostra foram considerados, não havendo critérios de aprovação ou desaprovação.

Foi utilizado o teste para a diferença entre duas proporções, para considerar a diferença entre êxito do sexo feminino e êxito do sexo masculino, com $\mathrm{p}=0,05$. Por meio do programa Excel, ainda foi utilizado o teste de intervalo de confiança para uma proporção, para comparar êxito e não êxito de cada sexo, com $\mathrm{p}=0,05$. Desse modo, foi possível assegurar em quais tarefas os êxitos tiveram significância estatística para o sexo masculino e para o sexo feminino.

É importante esclarecer que o termo êxito, descrito durante este estudo, foi adotado como representativo da obtenção de escore igual ou acima da metade do máximo de pontos possíveis em cada subtipo de tarefa, ou seja, igual ou superior a 5,00 , o que, conforme o teste utilizado, indica que a habilidade na tarefa em questão está consolidada ou adquirida.

Além disso, foram usados os testes não paramétricos de Wilcoxon, T-Test e o de Kruskal-Wallis, com valor de $\mathrm{p} \leq 0,10$, para verificar a interferência da variável sexo no desempenho de meninos e meninas, possibilitando compará-los por médias de ranking e analisar a presença ou ausência de relevância estatística.

\section{RESULTADOS}

As Tabelas 1 e 2 indicam o percentual de êxito, não êxito e a significância estatística, respectivamente, dos meninos e das meninas.

A Tabela 3 apresenta a comparação entre êxitos dos meninos e das meninas em cada tarefa de consciência fonêmica, com probabilidade de erro $\mathrm{p}=0,05$. Na quinta coluna desta tabela aparecem os valores de significância estatística $(\mathrm{p} \leq 0,10)$ obtidos pela organização dos escores de cada tarefa em médias de ranking (Teste não paramétrico de Wilcoxon) para representar a comparação entre o desempenho do sexo masculino e do sexo feminino.

Na Tabela 4 apresenta-se a média de acertos do sexo masculino e do sexo feminino. Destaca-se que não foi realizada análise estatística para comparação entre as médias de desempenho dos sexos masculino e feminino, em função da não homogeneidade de variância.

\section{DISCUSSÃO}

De acordo com a Tabela 1, é possível verificar que os meninos alcançaram resultados estatisticamente significantes, com escore maior ou igual a 5,00 (êxito), em exclusão de fonema inicial (T1 - Inicial), final (T1 - Final) e medial (T1 - Medial); em detecção de fonema inicial (T2 - Inicial), final (T2 - Final) e medial (T2 - Medial); em síntese fonêmica de palavras com três (T3 - 3 Fonemas), quatro (T3 - 4 Fonemas) e sete fonemas (T3 - 7 Fonemas); em segmentação fonêmica de palavras com três (T4 - 3 Fonemas), quatro (T4 - 4 Fonemas), cinco (T4 -

Tabela 1. Comparação entre êxito e não êxito para o sexo masculino em cada tarefa de consciência fonêmica

\begin{tabular}{|c|c|c|c|}
\hline Tarefas de consciência fonêmica & Êxito \% & Não-exito \% & $\begin{array}{c}\text { Significância } \\
\text { estatística }\end{array}$ \\
\hline T1 - Inicial (exclusão de fonema) & 100 & 0 & S \\
\hline T1 - Final (exclusão de fonema) & 100 & 0 & S \\
\hline T1 - Medial (exclusão de fonema) & 94,44 & 5,56 & $\mathrm{~S}$ \\
\hline T2 - Inicial (detecção de fonema) & 100 & 0 & S \\
\hline T2 - Final (detecção de fonema) & 100 & 0 & S \\
\hline T2 - Medial (detecção de fonema) & 94,44 & 5,56 & S \\
\hline T3 - 3 fonemas (síntese fonêmica) & 94,44 & 5,56 & S \\
\hline T3 - 4 fonemas (síntese fonêmica) & 88,89 & 11,11 & $S$ \\
\hline T3 - 5 fonemas (síntese fonêmica) & 61,11 & 38,89 & Ns \\
\hline T3 - 6 fonemas (síntese fonêmica) & 55,56 & 44,44 & Ns \\
\hline T3 - 7 fonemas (síntese fonêmica) & 22,22 & 77,78 & $\mathrm{~S}$ \\
\hline T4 - 3 fonemas (segmentação fonêmica) & 77,78 & 22,22 & S \\
\hline T4 - 4 fonemas (segmentação fonêmica) & 77,78 & 22,22 & $S$ \\
\hline T4 - 5 fonemas (segmentação fonêmica) & 83,33 & 16,67 & $S$ \\
\hline T4 - 6 fonemas (segmentação fonêmica) & 72,22 & 27,78 & S \\
\hline T4 - 7 fonemas (segmentação fonêmica) & 72,22 & 27,78 & $S$ \\
\hline T5 - 2 e 3 fonemas (reversão fonêmica) & 83,33 & 16,67 & $\mathrm{~S}$ \\
\hline T5 - 4 e 5 fonemas (reversão fonêmica) & 55,56 & 44,44 & Ns \\
\hline
\end{tabular}

Legenda: S - Significativo; Ns - Não significativo. Intervalo de confiança para uma proporção $\left({ }^{*} \mathrm{p}=0,05\right)$ 
Tabela 2. Comparação entre êxito e não êxito para o sexo feminino em cada tarefa de consciência fonêmica

\begin{tabular}{|c|c|c|c|}
\hline \multirow{2}{*}{ Tarefas de consciência fonêmica } & \multicolumn{2}{|c|}{ Meninas } & \multirow{2}{*}{$\begin{array}{c}\text { Significância } \\
\text { estatística }\end{array}$} \\
\hline & Exxito \% & Não-exito \% & \\
\hline T1 - Inicial (exclusão de fonema) & 100 & 0 & S \\
\hline T1 - Final (exclusão de fonema) & 100 & 0 & $\mathrm{~S}$ \\
\hline T1 - Medial (exclusão de fonema) & 100 & 0 & S \\
\hline T2 - Inicial (detecção de fonema) & 100 & 0 & S \\
\hline T2 - Final (detecção de fonema) & 94,44 & 5,56 & $\mathrm{~S}$ \\
\hline T2 - Medial (detecção de fonema) & 72,22 & 27,78 & S \\
\hline T3 - 3 fonemas (síntese fonêmica) & 100 & 0 & $S$ \\
\hline T3 - 4 fonemas (síntese fonêmica) & 94,44 & 5,56 & $S$ \\
\hline T3 - 5 fonemas (síntese fonêmica) & 66,67 & 33,33 & $\mathrm{~S}$ \\
\hline T3 - 6 fonemas (síntese fonêmica) & 66,67 & 33,33 & $S$ \\
\hline T3 - 7 fonemas (síntese fonêmica) & 44,44 & 55,56 & Ns \\
\hline T4 - 3 fonemas (segmentação fonêmica) & 88,89 & 11,11 & S \\
\hline T4 - 4 fonemas (segmentação fonêmica) & 88,89 & 11,11 & S \\
\hline T4 - 5 fonemas (segmentação fonêmica) & 83,33 & 16,67 & S \\
\hline T4 - 6 fonemas (segmentação fonêmica) & 77,78 & 22,22 & $\mathrm{~S}$ \\
\hline T4 - 7 fonemas (segmentação fonêmica) & 83,33 & 16,67 & $\mathrm{~S}$ \\
\hline T5 - 2 e 3 fonemas (reversão fonêmica) & 83,33 & 16,67 & S \\
\hline T5 - 4 e 5 fonemas (reversão fonêmica) & 55,56 & 44,44 & Ns \\
\hline
\end{tabular}

Legenda: S - Significativo; Ns - Não significativo. Intervalo de confiança para uma proporção ( $\left.{ }^{*} \mathrm{p}=0,05\right)$

Tabela 3. Comparação entre o desempenho de meninos e meninas em cada tarefa de consciência fonêmica e comparação do desempenho entre os sexos por estimativa de ranking

\begin{tabular}{|c|c|c|c|c|}
\hline Tarefas de consciência fonêmica & $\begin{array}{l}\text { Meninos } \\
\text { Éxito \% }\end{array}$ & $\begin{array}{c}\text { Meninas } \\
\text { Éxito \% }\end{array}$ & $\begin{array}{l}\text { Significância estatística } \\
\text { Teste de diferença entre } \\
\text { duas proporções }(p=0,05)\end{array}$ & $\begin{array}{l}\text { Meninos X Meninas } \\
\text { Estimativa de ranking } \\
(\mathrm{p} \leq 0,10)\end{array}$ \\
\hline T1 - Inicial (exclusão de fonema) & 100 & 100 & Ns & 0,9417 \\
\hline T1 - Final (exclusão de fonema) & 100 & 100 & Ns & 0,8563 \\
\hline T1 - Medial (exclusão de fonema) & 94,44 & 100 & Ns & 0,4706 \\
\hline T2 - Inicial (detecção de fonema) & 100 & 100 & Ns & 0,3365 \\
\hline T2 - Final (detecção de fonema) & 100 & 94,44 & Ns & 0,0689 \\
\hline T2 - Medial (detecção de fonema) & 94,44 & 72,22 & Ns & 0,8217 \\
\hline T3 - 3 fonemas (síntese fonêmica) & 94,44 & 100 & Ns & 0,8945 \\
\hline T3 - 4 fonemas (síntese fonêmica) & 88,89 & 94,44 & Ns & 0,6040 \\
\hline T3 - 5 fonemas (síntese fonêmica) & 61,11 & 66,67 & Ns & 0,9238 \\
\hline T3 - 6 fonemas (síntese fonêmica) & 55,56 & 66,67 & Ns & 0,8358 \\
\hline T3 - 7 fonemas (síntese fonêmica) & 22,22 & 44,44 & Ns & 0,3876 \\
\hline T4 - 3 fonemas (segmentação fonêmica) & 77,78 & 88,89 & Ns & 0,4481 \\
\hline T4 - 4 fonemas (segmentação fonêmica) & 77,78 & 88,89 & Ns & 0,4709 \\
\hline T4 - 5 fonemas (segmentação fonêmica) & 83,33 & 83,33 & Ns & 0,5772 \\
\hline T4 - 6 fonemas (segmentação fonêmica) & 72,22 & 77,78 & Ns & 0,2511 \\
\hline T4 - 7 fonemas (segmentação fonêmica) & 72,22 & 83,33 & Ns & 0,4057 \\
\hline T5 - 2 e 3 fonemas (reversão fonêmica) & 83,33 & 83,33 & Ns & 0,7709 \\
\hline T5 - 4 e 5 fonemas (reversão fonêmica) & 55,56 & 55,56 & Ns & 0,7023 \\
\hline
\end{tabular}

Legenda: Ns - Não significativo. Teste de diferença entre duas proporções $(p=0,05)$. Teste de Wilcoxon $(p \leq 0,10)$. 
Tabela 4. Média de acertos obtidos por meninos e meninas em cada tarefa de consciência fonêmica*

\begin{tabular}{lcc}
\hline Tarefas de consciência fonêmica & \multicolumn{2}{c}{ Média de acertos } \\
\cline { 2 - 3 } & Meninos & Meninas \\
\hline T1 - Inicial (exclusão de fonema) & 9,78 & 9,61 \\
T1 - Final (exclusão de fonema) & 9,67 & 9,56 \\
T1 - Medial (exclusão de fonema) & 9,17 & 9,72 \\
T2 - Inicial (detecção de fonema) & 9,33 & 9,06 \\
T2 - Final (detecção de fonema) & 9,06 & 8,22 \\
T2 - Medial (detecção de fonema) & 7,11 & 7,00 \\
T3 - 3 fonemas (síntese fonêmica) & 8,56 & 8,56 \\
T3 - 4 fonemas (síntese fonêmica) & 8,17 & 8,06 \\
T3 - 5 fonemas (síntese fonêmica) & 5,89 & 6,00 \\
T3 - 6 fonemas (síntese fonêmica) & 6,06 & 6,39 \\
T3 - 7 fonemas (síntese fonêmica) & 3,83 & 4,67 \\
T4 - 3 fonemas (segmentação fonêmica) & 7,50 & 8,33 \\
T4 - 4 fonemas (segmentação fonêmica) & 7,56 & 8,56 \\
T4 - 5 fonemas (segmentação fonêmica) & 7,61 & 8,06 \\
T4 - 6 fonemas (segmentação fonêmica) & 7,00 & 7,94 \\
T4 - 7 fonemas (segmentação fonêmica) & 6,94 & 7,89 \\
T5 - 2 e 3 fonemas (reversão fonêmica) & 7,83 & 7,78 \\
T5- 4 e 5 fonemas (reversão fonêmica) & 5,56 & 5,33 \\
\hline
\end{tabular}

*Valor máximo de acertos $=10$

5 Fonemas), seis (T4 - 6 Fonemas) e sete fonemas (T4 - 7 Fonemas) e em reversão fonêmica com dois e três fonemas (T5 - 2 e 3 Fonemas). Em apenas três, das 18 tarefas, não se observaram diferenças estatisticamente significantes entre êxitos e não êxitos.

A Tabela 2 aponta, que no caso das meninas, não houve diferença significante do ponto de vista estatístico entre êxitos e não êxitos, apenas nas tarefas de síntese fonêmica com palavras de sete fonemas (T3 - 7 Fonemas) e de reversão fonêmica com palavras de quatro e cinco fonemas (T5 - 4 e 5 Fonemas). Em todas as demais tarefas que testam a habilidade de consciência fonêmica, é possível afirmar, com segurança, que o sexo feminino obteve êxito.

Com base nesses resultados, verifica-se na Tabela 3 que, ao se considerar a probabilidade de erro $\mathrm{p}=0,05$, a variável sexo parece não interferir, de modo estatisticamente significante, na performance de nenhuma das tarefas avaliadas, corroborando outros estudos $^{(3,20-21,24)}$. Por outro lado, o teste não paramétrico com $\mathrm{p} \leq 0,10$ revelou que, na tarefa de detecção de fonema final (T2 - Final), o desempenho do sexo feminino foi diferente do sexo masculino, ou melhor, inferior, confirmando os achados de pesquisa em que a interferência da variável sexo foi relevante no desempenho das tarefas em consciência fonológica ${ }^{(23)}$, embora a favor das meninas.

Destaca-se que, a detecção de fonemas pode ser realizada na ausência de consciência fonêmica em virtude de que pistas fonéticas, como duração e intensidade do fonema, auxiliam a detecção, podendo ser considerada uma forma holística de consciência fonológica(3).

Analisando as medidas brutas de desempenho, constata- se, ainda na Tabela 3, uma tendência do desempenho do sexo feminino ser melhor que o do masculino na maioria das tarefas. Este dado é consoante com os resultados de pesquisa que fez uso do mesmo instrumento de avaliação ${ }^{(23)}$. Nesse sentido, as meninas obtiveram valor percentual de êxito superior à freqüência de êxito dos meninos em todas as tarefas fonêmicas, exceto naquelas em que o êxito foi igual entre os sexos e nas tarefas de detecção de fonema medial e final (T2 - Medial e Final).

A porcentagem de êxitos de meninos e meninas foi exatamente igual nas seguintes tarefas: exclusão de fonema inicial (T1 - Inicial); exclusão de fonema final (T1 - Final); detecção de fonema inicial (T2 - Inicial); segmentação fonêmica de palavras com cinco fonemas (T4 - 5 Fonemas); reversão fonêmica de palavras com dois e três fonemas (T5 - 2 e 3 Fonemas) e com quatro e cinco fonemas (T5- 4 e 5 Fonemas).

As divergências entre os achados do presente estudo, que revelam desempenhos distintos em meninos e em meninas, em contraposição aos resultados de estudos em que não se observou diferença entre sexos no desempenho de habilidades em consciência fonológica, podem ser justificadas. Os autores destas pesquisas $^{(3,20-21,25)}$ utilizam instrumentos de avaliação da consciência fonológica menos abrangentes, com cruzamento de variáveis e menos itens testados dentro da tarefa de consciência fonêmica.

Desse modo, o Protocolo de Tarefas de Consciência Fonológica $^{(2)}$, utilizado neste estudo, avalia com maior número de itens cada uma das tarefas, subdividindo-as de acordo com a extensão da palavra ou posição da sílaba/fonema na palavra, requerendo a memória em um nível crescente de dificuldades.

O teste de consciência fonêmica do Protocolo de Tarefas de Consciência Fonológica avalia, por exemplo, cinco itens partindo do mais simples ao mais complexo. Há, ainda, uma escala de pontuação, que permite analisar a média de acertos de cada tarefa, o que nem sempre ocorre em outros estudos.

Na terceira tabela, é possível constatar que tanto as meninas como os meninos apresentaram menor número de êxitos na tarefa de síntese fonêmica de palavras com sete fonemas (T3 - 7 Fonemas). Logo, essa tarefa foi a de maior dificuldade para ambos os sexos. Esse achado é condizente com o argumento de que se deve considerar que o comprimento de uma palavra pode influenciar os escores nas habilidades de síntese e de segmentação fonêmica ${ }^{(2,21)}$. Além disso, considerando a idade das crianças deste estudo (entre sete e oito anos) e, comparando o desempenho alcançado com o de outras pesquisas, há achados semelhantes ${ }^{(2,24)}$, em que a síntese fonêmica aparece entre as tarefas mais difíceis envolvendo o nível dos fonemas. Esse fato, provavelmente, pode ser explicado pela demanda de atenção e de memória que essa tarefa exige ${ }^{(2)}$.

Por outro lado, meninos e meninas apresentaram menor dificuldade em tarefas de exclusão fonêmica em posição inicial (T1-Inicial) e final (T1-Final) e em detecção fonêmica em posição inicial (T2-Inicial). Este resultado vem ao encontro de achados de outra pesquisa ${ }^{(2)}$ na qual se afirma que, nestas tarefas, as crianças entre sete e oito anos, geralmente, obtém $100 \%$ de sucesso.

Através de uma análise qualitativa da média de acertos alcançada nas tarefas de consciência fonêmica em cada sexo 
(Tabela 4), é possível reforçar que o desempenho das meninas foi superior à performance dos meninos, na maioria das tarefas (nove das dezoito tarefas). São elas: exclusão de fonema medial (T1 - Medial); síntese de palavras com cinco (T3 - 5 Fonemas), seis (T3 - 6 Fonemas) e sete fonemas (T3 - 7 Fonemas) e em todas as tarefas de segmentação fonêmica (T4).

Em contrapartida, os meninos saíram-se melhor em: exclusão de fonema inicial (T1 - Inicial) e final (T1 - Final); detecção de fonemas (T2 - Inicial, final e medial); síntese fonêmica com palavras de quatro fonemas (T3 - 4 Fonemas) e em reversão fonêmica (T5 - 2, 3, 4 e 5 Fonemas), ou seja, em oito tarefas. A média do desempenho em síntese fonêmica de palavras com três fonemas (T3 - 3 Fonemas) foi exatamente igual para ambos os sexos.

Destaca-se, que o sexo masculino obteve mais porcentagem de êxito e melhor média na tarefa de reversão fonêmica com palavras de dois e três fonemas ( $\mathrm{T} 5$ - 2 e 3 Fonemas) que o sexo oposto. A reversão de fonemas pode ser considerada uma das tarefas mais dependentes da consciência fonêmica, já que exige o isolamento e a manipulação de cada fonema da palavra, para que sua ordem possa ser modificada ${ }^{(2,4)}$. Portanto, apesar de os meninos apresentarem desempenho inferior às meninas, em grande parte das tarefas em consciência fonêmica, eles se saíram melhor nas tarefas de reversão fonêmica, contradizendo achados da literatura $^{(23)}$, provavelmente, em função do número mais restrito de participantes no presente estudo.

Dentro desse contexto, na tentativa de explicar e, corroborando os achados com relação à reversão fonêmica, cita-se um estudo que afirma que as meninas, apesar de serem mais fluentes verbalmente (produzirem mais palavras com coda), não são tão perspicazes nas suas produções quanto os meni$\operatorname{nos}^{(19)}$. Nessa pesquisa, o sexo masculino apresentou resultados estatisticamente significantes de maior probabilidade de produção correta da coda em relação às meninas. A autora ainda acrescenta que essa constatação representa que as crianças do sexo masculino são mais detalhistas, se preocupando mais com a produção correta do fonema, enquanto que as do sexo feminino se preocupam em falar mais, mesmo que "errado".

É importante considerar que o sexo feminino apresentou melhor desempenho em tarefas de síntese e segmentação fonêmica envolvendo maior número de fonemas e, ao encontro de resultados de outro estudo, possivelmente, essa condição implique maior domínio do código alfabético ${ }^{(2)}$.

De acordo com os argumentos apresentados, se considera que o sexo feminino apresentou um desempenho levemente superior ao masculino, nas habilidades envolvendo os fonemas. Esse fato permite supor que as meninas tendem à maior facilidade para a aquisição e aprendizagem da leitura e da escrita, segundo evidências científicas ${ }^{(9)}$. Além disso, estudos demonstram que as meninas possuem melhor desempenho inicial já ao começarem a aprender a ler e a escrever ${ }^{(1,13)}$.

Diversas pesquisas indicam a consciência fonêmica como aspecto facilitador e preditor do sucesso na leitura, evidenciando a importância do desenvolvimento dessa habilidade ${ }^{(7-9)}$. Logo, programas de estimulação em consciência fonológica podem ser de extremo valor para facilitar meninos e meninas no processo de aprendizagem da leitura e da escrita do modo efetivo. Pesquisas sobre o assunto parecem representar um importante caminho para estudiosos da área.

Quanto ao melhor desempenho, de modo geral, das meninas nas habilidades em consciência fonêmica, uma possível explicação pode estar relacionada ao fato de exames de neuroimagem comprovarem que homens e mulheres processam a linguagem de forma diferente ${ }^{(13)}$ e que o processamento é melhor nas mulheres ${ }^{(16)}$. Há indícios de que, no sexo feminino, as áreas de Broca e de Wernicke mostram-se maiores e isto também poderia explicar, biologicamente, um melhor desempenho feminino nas tarefas relacionadas à linguagem ${ }^{(17)}$. Além disso, pesquisadores afirmam que o lóbulo parietal inferior direito, área associada ao processo de atenção e percepção seletiva, bem como à capacidade de concentrar-se em um estímulo específico e em detalhes, é sutilmente maior em mulheres ${ }^{(18)}$.

Há, também, pesquisas que mostram que o hemisfério cerebral esquerdo das meninas se desenvolve mais depressa do que o dos meninos, o que justificaria o fato de elas falarem mais cedo, conseguirem ler antes e aprenderem mais facilmente uma segunda língua. Já nos meninos, o hemisfério direito do cérebro amadurece mais cedo que nas meninas, garantindo-lhes vantagens em percepção, lógica, orientação espacial, matemática, resoluções de problemas, entre outras habilidades ${ }^{(13)}$.

No que concerne à discriminação auditiva, as meninas são capazes de identificar a voz da mãe ou diferenciar o choro de outro bebê, entre os sons do ambiente, com apenas uma semana de vida, não ocorrendo o mesmo para o sexo masculino. $\mathrm{O}$ cérebro feminino tem a capacidade de isolar e selecionar sons e de tomar decisões a respeito de cada um deles, enquanto que, para os meninos, a visão é o sentido mais aguçado ${ }^{(26)}$.

Finalizando a discussão dos resultados, cabe aos estudiosos e pesquisadores em consciência fonológica divulgar suas investigações e resultados no meio educacional, orientando, assessorando e incentivando o corpo docente a efetivar a instrução explícita em sala de aula, enfatizando as habilidades em consciência fonêmica e independente da variável sexo.

Destaca-se ainda, considerando-se que todo o grupo pesquisado neste estudo consistiu de crianças provenientes de escola particular, que poder-se-ia supor que os resultados desta pesquisa devessem ficar circunscritos a este tipo de população. No entanto, há pesquisas ${ }^{(27-28)} \mathrm{em}$ que não foram encontradas diferenças significantes no desempenho de tarefas em consciência fonêmica, mesmo após estimulação em consciência fonológica $^{(27)}$, entre estudantes de escolas públicas e particulares, sugerindo que esta não seja uma variável interveniente.

Além disso, as observações tecidas a respeito a respeito do fator sexo merecem corroboração de novos estudos com uma amostra maior, talvez envolvendo exames de neuroimagem e outros níveis de escolaridade.

\section{CONCLUSÃO}

A partir dos resultados obtidos, foi possível verificar que houve diferença, estatisticamente significante, a favor dos meninos apenas na tarefa de detecção de fonema em posição final.

Apesar de não haver significância estatística entre o desempenho de meninos e meninas, nas demais tarefas em consciência fonêmica, verificou-se uma tendência de melhor 
desempenho do sexo feminino, principalmente, nas palavras com maior número de fonemas.

A tarefa em que as crianças de ambos os sexos apresentaram maior dificuldade, considerando-se o fator idade, foi a de síntese fonêmica com palavras de até sete fonemas. Já, as de menor complexidade foram as de exclusão fonêmica em posição inicial e final e as de detecção fonêmica em posição inicial.

\begin{abstract}
Purpose: To verify the influence of the variable gender in children's performance on phonemic awareness tasks. Methods: The sample consisted of 36 second grade students from an elementary school: 18 girls and 18 boys. All of them were submitted to hearing screening, speech-language assessment and evaluation of phonemic awareness abilities. Results: In general, the statistical analysis did not reveal significant differences between genders. However, qualitatively, it was observed that girls were more successful than boys in all segmentation and phonemic synthesis tasks, which impact the analysis of smaller elements. Conclusions: Although no statistically significant differences were found between genders, it was verified that girls presented better phonemic awareness abilities.
\end{abstract}

Keywords: Language; Students; Child; Speech therapy; Sex distribution

\section{REFERÊNCIAS}

1. Capellini SA, Ciasca SM. Avaliação da consciência fonológica em crianças com distúrbio específico de leitura e escrita e distúrbio de aprendizagem. Temas Desenvolv. 2000;8(48):17-23.

2. Cielo CA. Habilidades em consciência fonológica em crianças de 4 a 8 anos de idade. Pró-Fono. 2002;14(3):301-12.

3. Barrera SD, Maluf MR. Consciência metalingüística e alfabetização: um estudo com crianças da primeira série do ensino fundamental. Psicol Reflex Crít. 2003;16(3):491-502.

4. Laing SP, Espeland W. Low intensity phonological awareness training in a preschool classroom for children with communication impairments. J Commun Disord. 2005;38(1):65-82.

5. Valente F, Alves Martins M. Competências metalingüísticas e aprendizagem da leitura em duas turmas do $1^{\circ}$ ano de escolaridade com métodos de ensino diferentes. Aná Psicológica. 2004;22(1):193-212.

6. Gombert JE, Colé P. Activités metalinguistiques, lecture et illetrisme. In: Kail M, Fayol M. L'acquisition du language. Paris: PUF; 2000. p. 117-50.

7. Lamprecht RR. Aquisição fonológica do português: perfil de desenvolvimento e subsídios para a terapia. Porto Alegre: Artmed; 2004.

8. Kirby JR, Parrila RK, Pfeiffer SL. Naming speed and phonological awareness as predictors of reading development. J Educ Psychol. 2003;95(3):453-64.

9. Schatschneider C, Fletcher JM, Francis DJ, Carlson CD, Foorman B. Kindergarten prediction of reading skills: a longitudinal comparative analysis. J Educ Psychol. 2004;96(2):265-82.

10. Caravolas M, Volín J, Hulme C. Phoneme awareness is a key component of alphabetic literacy skills in consistent and inconsistent orthographies: evidence from Czech and English children. J Exp Child Psychol. 2005;92(2):107-39.

11. Guimarães SRK. Dificuldades no desenvolvimento da lectoescrita: o papel das habilidades metalingüísticas. Psicol Teor Pesqui. 2003;19(1):33-45.

12. Olinto MTA. Reflexões sobre o uso de conceito de gênero e/ou sexo na epidemiologia: um exemplo nos modelos hierarquizados de análise. Rev Bras Epidemiol. 1998;1(2):161-9.

13. Vallet RE. Fatores neuropsicológicos críticos. In: Vallet RE. Dislexia: uma abordagem neuropsicológica para a educação de crianças com graves desordens de leitura. São Paulo: Manole; 1990. p. 11-7.

14. Pollack W. Escolas: a bagunça do quadro negro. In: Pollack W. Meninos de verdade: conflitos e desafios na educação de filhos homens. São Paulo: Alegro; 1999. p. 265-309.

15. Capellini SA, Padula NAMR, Santos LCA, Lourenceti MD,
Carrenho EH, Ribeiro LA. Desempenho em consciência fonológica, memória operacional, leitura e escrita na dislexia familial. Pró-Fono. 2007;19(4):374-80.

16. Rabinowicz T, Dean DE, Petetot JM, de Courten-Myers GM. Gender differences in the human cerebral cortex: more neurons in males; more processes in females. J Child Neurol. 1999;14(2):98-107.

17. Knaus TA, Bollich AM, Corey DM, Lemen LC, Foundas AL. Sexlinked differences in the anatomy of the perisylvian language cortex: a volumetric MRI study of gray matter volumes. Neuropsychology. 2004;18(4):738-47.

18. Luders E, Narr KL, Thompson PM, Rex DE, Jancke L, Steinmetz H, Toga AW. Gender differences in cortical complexity. Nat Neurosci. 2004;7(8):799-800.

19. Mezzomo CL. Aquisição da coda no português brasileiro: uma análise via teoria de princípios e parâmetros. [Tese]. Porto Alegre: Faculdade de Letras da Pontifica Universidade Católica do Rio Grande do Sul; 2003.

20. Wallach L, Wallach MA, Dozier MG. Poor children learning to read do not have trouble with auditory discrimination but do have trouble with phoneme recognition. J Educ Psychol. 1977;69(1):36-9.

21. Salles JF, Mota HB, Cechella C, Parente MAMP. Desenvolvimento da consciência fonológica de crianças de primeira e segunda séries. PróFono. 1999;11(2):68-76.

22. Meneses MS, Lozi GP, Souza LR, Assencio-Ferreira VJ. Consciência fonológica: diferenças entre meninos e meninas. Rev CEFAC. 2004;6(3):242-6.

23. Andreazza-Balestrin CA. Relação entre desempenho em consciência fonológica e a variável sexo, na infância. [Dissertação]. Santa Maria: Universidade Federal de Santa; 2007.

24. Souza LBR. Consciência fonológica em um grupo de escolares da $1^{\text {a }}$ série do $1^{\circ}$ grau em Natal - RN. Rev Soc Bras Fonoaudiol. 2005;10(1):12-7.

25. Araújo FP, Lindenbaum J, Figueiredo FV, Chiappetta ALML. A consciência fonológica do português na aquisição simultânea de duas línguas. Rev CEFAC. 2006;8(1):15-9.

26. Pease A, Pease B. Porque os homens fazem sexo e as mulheres fazem amor? Uma visão científica (e bem humorada de nossas diferenças). Rio de Janeiro: Sextante; 2000.

27. Capovilla AGS, Capovilla FC. Efeitos do treino de consciência fonológica em crianças com baixo nível sócio-econômico. Psicol Reflex Crít. 2000;13(1):7-24.

28. Pedras CTPA, Geraldo T, Crenitte PAP. Consciência fonológica em crianças de escola pública e particular. R Soc Bras Fonoaudiol. 2006;11(2):65-9. 